\title{
Lessons from Partial Hospital Evacuations after the 2016 Central Tottori Earthquake
}

\author{
Tomofumi Ogoshi ${ }^{*}$, Takahiro Ueda1, Masato Homma1, Masafumi Kameoka1, \\ Hiroshi Ichibakase ${ }^{1}$, Takafumi Hamasaki², Minoru Okada ${ }^{3}$ \\ ${ }^{1}$ Department of Emergency, Tottori University Hospital, Tottori, Japan \\ ${ }^{2}$ Department of Surgery, Tottori Prefectural Kousei Hospital, Tottori, Japan \\ ${ }^{3}$ Department of Emergency, Tottori University Central Hospital, Tottori, Japan \\ Email: *tomofumi-o@nifty.com
}

How to cite this paper: Ogoshi, T., Ueda, T., Homma, M., Kameoka, M., Ichibakase, H., Hamasaki, T. and Okada, M. (2021) Lessons from Partial Hospital Evacuations after the 2016 Central Tottori Earthquake. Open Journal of Emergency Medicine, 9, 216-223.

https://doi.org/10.4236/ojem.2021.94022

Received: September 28, 2021

Accepted: December 11, 2021

Published: December 14, 2021

Copyright $\odot 2021$ by author(s) and Scientific Research Publishing Inc. This work is licensed under the Creative Commons Attribution International License (CC BY 4.0).

http://creativecommons.org/licenses/by/4.0/

\begin{abstract}
Objective: This study investigated the reasons, timing, procedures, and priorities of evacuations implemented by hospitals after the 2017 Central Tottori Earthquake to determine whether the evacuations were conducted appropriately. Methods: We collected patient and hospital data from the Disaster Medical Assistance Team (DMAT) coordination headquarters at the Prefectural Office. Requests for the transfer of 13 patients were analyzed. Results: The 13 patients were evacuated at night over seven hours, during which aftershocks occurred and falling debris was a high risk. We determined that none of the affected regions had emergency needs. Therefore, patient transport could have been conducted the following morning by bus and helicopter. Furthermore, patient transport could be efficiently carried out without physicians accompanying the patients. Nonetheless, consideration should be made regarding the handling of patient issues while in transit. Where a high number of patients are transported, hospitals would need to request the assistance of DMAT and Self-Defense Forces units earlier. Conclusions: Although all patients were successfully evacuated without incident with a few DMAT, It took for 7 hours to transfer 13 patients So hospitals should consider transporting patients during the day if there is no risk of building collapse. Hospitals should also prepare a plan for evacuation priority before the next disaster.
\end{abstract}

\section{Keywords}

DMAT, Earthquake, Kurayoshi, Partial Hospital Evacuation, Tottori

\section{Introduction}

On October 21, 2017, an M6.6 earthquake, the Central Tottori Earthquake, 
struck at 9:07 pm with a focal depth of $11 \mathrm{~km}$ (Figure 1). In the central Tottori Prefecture region, the seismic intensity was lower than 6 on the Japanese seismic scale. Although it was confirmed that no deaths occurred in the eastern and western regions of the prefecture following the earthquake, Dr. Minoru Okada of Tottori Central Hospital established a DMAT headquarters in the Prefectural Office (Figure 2). At 4:18 pm, deployment of the Tottori DMAT was requested, prompting 2 DMAT team to meet at Tottori Prefectural Kosei Hospital in the city of Kurayoshi.

Based on a prior arrangement, two fire stations within the prefecture provided ten units, and two fire stations in the city of Okayama sent four units, making a total of 14 units (41 individuals). Additionally, a helicopter ambulance was sent from Hyogo Prefecture to the Kurayoshi Fire Station; at 4:49 pm, the Toyooka Hospital team established a DMAT headquarters at Tottori Prefectural Kosei Hospital. Information collected on the conditions of regional hospitals determined that six of the 11 hospitals had interrupted water service, one had an electric power outage, and another had suffered physical damage (Figure 2). Requests for evacuations were received from Hospital A, which was unable to provide dialysis or meals (due to interruption of water service). Therefore, at 5:26 $\mathrm{pm}$, a request was submitted to the Tottori DMAT and two other teams to assist

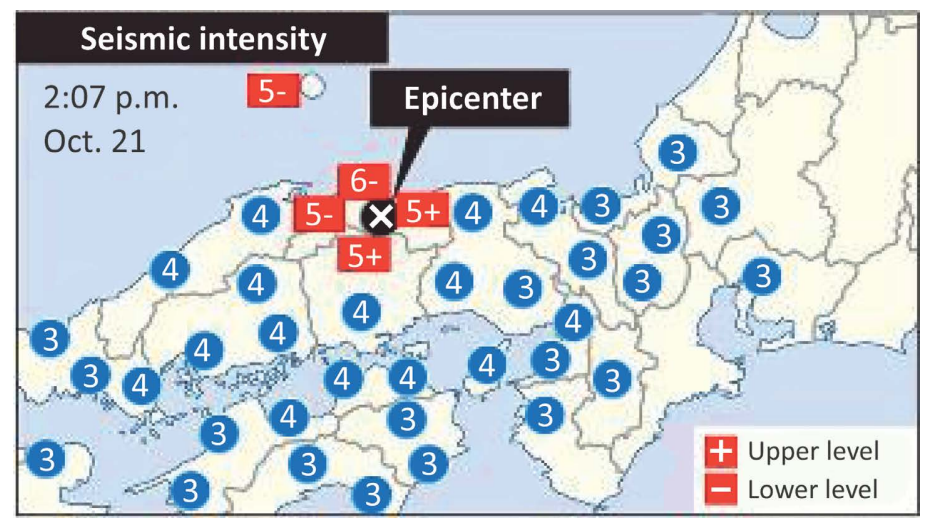

Figure 1. Seismic intensity of the 2016 Central Tottori earthquake in Japan.

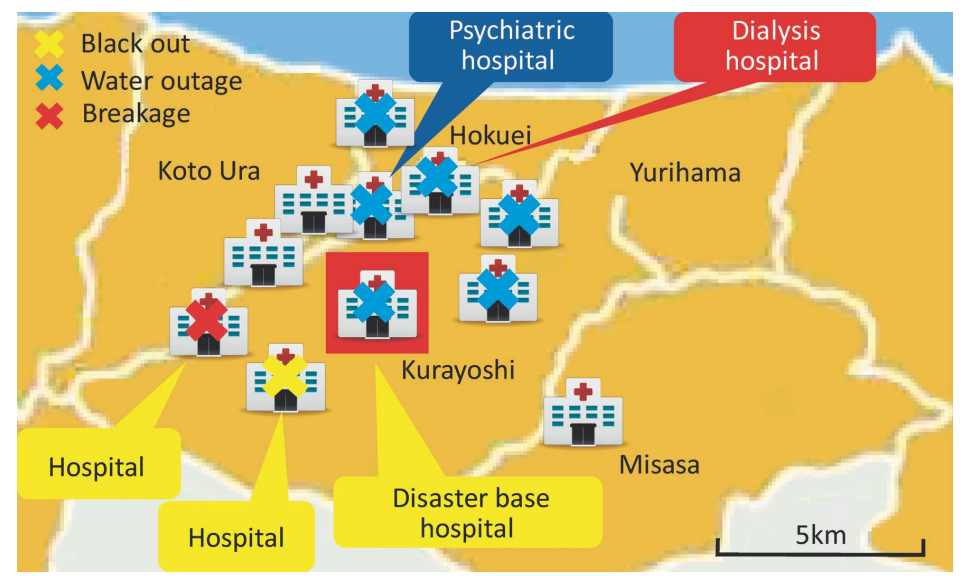

Figure 2. Damaged hospital in Kurayoshi city. 
in the hospital evacuation. 13 patients were wanted to be evacuated to other hospitals from 2 hospitals and were transported out of the hospital over approximately six hours with no reported deaths.

On April 14, 2016, an M6.5 earthquake occurred in Kumamoto Prefecture of Japan, causing damage to hospitals in the vicinity. Although they were temporarily unable to function, the hospitals continued to provide care for in-hospital patients. However, on April 16, a second earthquake of M7.3 occurred, damaging many hospitals so extensively that they were in danger of collapse. Consequently, 17 hospitals had to be fully evacuated [1]. Fukae reported that Kumamoto City Hospital suffered structural damage that interrupted water services; consequently, it took 13 hours to successfully transport 310 patients using a disaster medical assistance team (DMAT) to another hospital with no casualties [2]. Conversely, during the Great West Japan Earthquake, Futaba Kosei Hospital was evacuated for several days, during which one patient died [3]. Six months later, an M6.6 earthquake struck in central Tottori Prefecture.

This study investigates whether hospitals should have been partially evacuated at night. Emergency medical technicians alone rarely transfer patients to other hospitals; although the earthquake was low in severity and urgency, it was decided that the patients should be transferred at midnight.

\section{Methods}

In the wake of the Central Tottori Earthquake, three hospitals requested a transfer of their patients. Six patients requested to be evacuated, and the hospitals where they were being treated made the requests for the remaining seven patients, leading to 13 patients being transferred. The condition of the patients was not serious, and they did not have to be evacuated immediately. Consequently, hospital staff waited until the following morning to evacuate the patients. The patients' data were collected from the DMAT coordination headquarters at the Prefectural Office. This study investigated the reasons, timings, and procedures of the evacuations, the evacuation priorities, and other factors to determine whether the evacuations were conducted appropriately.

\section{Results}

Eventually, requests to transfer 13 patients to different hospitals were received. The specific types and numbers of patients to be evacuated were as follows: chronic renal failure (6), aspiration pneumonia (1), herpes zoster (2), drug rash (1), bedsores (1), esophageal varices rupture (1), and femoral neck fracture (1) (Figure 3). Consequently, the Prefectural DMAT Headquarters arranged for hospitals to receive the patients, orchestrated the transport procedures, and formulated plans for all 13 patients to be transported to hospitals located in the eastern and western regions of the prefecture. All patient data were collected by the DMAT Headquarters and sent to the Central Fire Department. The conditions of all patients were stable, except for one, who did not require continuous 


\begin{tabular}{|c|c|c|c|c|c|}
\hline & Age & Gender & Illness & ADL & Medical treatment \\
\hline 1. & $36 y r s$ & $\mathrm{~F}$ & Drug rash & Self-reliant & Infusion \\
\hline 2. & $86 y r s$ & $\mathrm{~F}$ & Pneumonia & Self-reliant & Infusion \\
\hline 3. & $74 y r s$ & $\mathrm{~F}$ & Renal failure & Bedridden & Gastric fistula, dialysis \\
\hline 4. & $85 y r s$ & $\mathrm{~F}$ & Renal failure & Bedridden & Dialysis \\
\hline 5. & $96 y r s$ & $\mathrm{~F}$ & Bedsores & Bedridden & None \\
\hline 6. & $97 y r s$ & $\mathrm{~F}$ & Renal failure & Bedridden & Dialysis \\
\hline 7. & $86 y r s$ & $M$ & Renal failure & Bedridden & Dialysis \\
\hline 8. & $70 y r s$ & $\mathrm{~F}$ & Herpes zoster & Self-reliant & Infusion \\
\hline 9. & $90 y r s$ & $\mathrm{~F}$ & Herpes zoster & light needed support & Infusion \\
\hline 10. & $51 y r s$ & $\mathrm{~F}$ & Renal failure & Self-reliant & Dialysis \\
\hline 11. & $50 y r s$ & $M$ & Esophageal varices rupture & light needed support & Infusion, hemostasis \\
\hline 12. & $96 y r s$ & $\mathrm{~F}$ & Fracture on femur & light needed support & Infusion, operation \\
\hline 13. & $62 y r s$ & $\mathrm{~F}$ & Renal failure & light needed support & Dialysis \\
\hline
\end{tabular}

Figure 3. List of patients evacuated to other hospitals.

medical intervention. All ambulances used for transport were procured and dispatched from the Central Fire Department. The hospital evacuations began at 7:30 pm, and by 2:00 am the following morning, a total of 12 patients had arrived at the hospitals that agreed to receive them (Figure 4). A list of the $13 \mathrm{pa}$ tients evacuated is provided in Figure 3; all were in a stable condition on arrival at the hospitals.

\section{Limitations}

As there were only about 50,000 people in this area, and very few patients were affected by the earthquake, a limitation of our study is the small sample size. So there is a few DMAT in my prefecture and there is also no emergency center located in the area. Studies that consider other areas with an emergency center might show different results.

\section{Discussion}

An investigation of the hospital evacuations' timing revealed that each process was different based on each hospital's post-earthquake situation. Fukae et al. reported that, in the case of the Kumamoto Earthquake, due to the risk of falling debris, interruption of essential services (such as water and electric power), and continuous aftershocks measuring between $4 \mathrm{M}$ and $6 \mathrm{M}$ in seismic intensity, it was decided to evacuate hospitals [2]. Tohoku University has an evacuation plan to be implemented upon the announcement of a "Level 4" disaster warning, which indicates a large-scale fire or severe building damage [4]. However, if essential public services are not interrupted-even in an event during which structural damage has occurred-the plan stipulates that, while continuous assessment is required, early evacuation is not necessary [5]. As it took seven hours to transport the 13 patients in Tottori, aftershocks occurred throughout the night, and there was a danger of falling debris, it may have been prudent to transport the patients the following morning by bus and helicopter [4].

An investigation into the reasons for determining to evacuate hospitals revealed the following. Homma et al. reported that hospital managers followed 


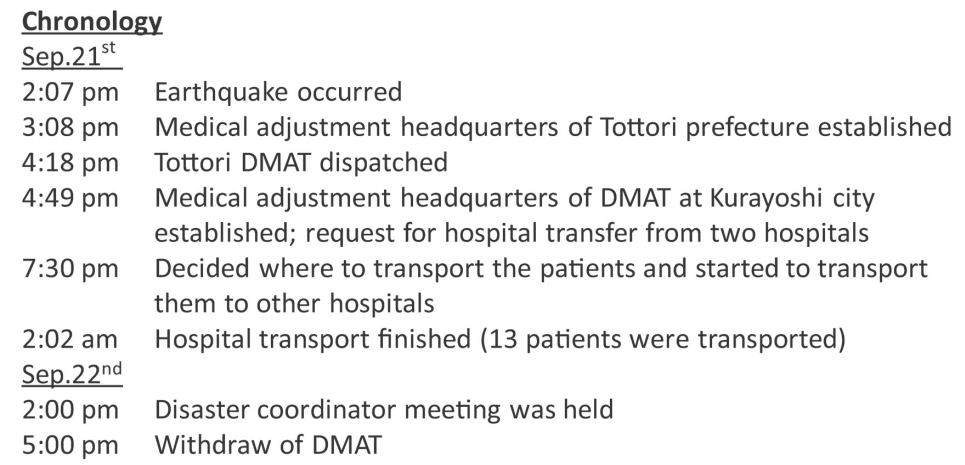

Figure 4. Chronology of DMAT headquarters.

specific criteria for making such judgments, and the reasons for evacuating hospitals included the interruption of essential public services, the danger of landslides, nuclear accidents, rupture of water pipes, clear inability to continue providing medical care due to large aftershocks following partial damage to the hospital building from the initial earthquake, and high levels of employee anxiety [6]. In the case of the Northridge (California, USA) earthquake, six water leakages occurred at three hospitals due to ruptured sprinkler systems, rooftop water tanks, and water pipes [5].

Ukai et al. reported that, in the case of the Hanshin Earthquake, it was necessary to evacuate hospitals for the same types of water leaks [7]. Kazuma et al. reported that dialysis patients are sometimes evacuated as quickly as possible to distant locations because they require large amounts of water [8]. During the Central Tottori Earthquake, which experienced similar destruction, although the buildings were damaged, they were eventually determined to be repairable, with few essential public services being interrupted. Thus, although it was unnecessary to evacuate all patients from hospitals, requests were placed to evacuate 13 patients. Patients made the requests directly because they were anxious about whether their care could be provided in the area affected by the earthquake. Physicians made requests because of patients on dialysis or that needed to be evacuated for surgery. Although the level of urgency associated with patient anxiety is lower, if they stayed and became panicked, it would take up the time and energy of the physicians, and so the evacuation was considered as soon as possible.

An examination of hospital evacuation procedures revealed the following. During the Kumamoto Earthquake, the DMAT managed the evacuations [1]. Yamana et al. reported that there are cases in which even patients with mild symptoms can experience lowered blood pressure when transferred to another hospital and that it is beneficial for medical teams to accompany patients so that they can handle any patient issues that may arise during transit [9]. Yamagata et al. reported that evacuations could be handled smoothly through the use of private and Self-Defense Force units [1]. For the cases investigated in this study, it was determined that there were no emergency needs at any of the affected re- 
gions and that emergency units from other areas whose assistance had been requested could transport patients on their return to their home bases. Thus, patient transport could be efficiently carried out without physicians accompanying the patients. However, it must still be considered how patient issues could have been handled while in transit. In cases for which the number of patients who are transported is higher, it would be necessary to request the assistance of DMAT and Self-Defense Force units earlier.

An investigation of evacuation priorities revealed the following. Five of the six hospitals that were completely evacuated due to the Northridge Earthquake held patients in a serious condition, and one of the hospitals included patients with mild illnesses [3]. As children and newborns are vulnerable to experiencing drops in body temperature during transit, they should have been high on the priority list for transport [10]. However, they seemed to be placed lower in priority, which indicates that a different triage tool may be required [11] [12] [13] [14]. Our investigation of a patient who experienced esophageal varices shock indicated that, although the patient was transported with an accompanying physician at an early stage because the other patients were not children, were relatively calm, and could be easily transported, they focused on prioritizing the evacuation order. However, we believe that a plan to prioritize evacuation orders should be made in the future.

Future issues include that, heavy equipment for removing debris and emergency medical facilities are needed to help deal with the aftermath of an earthquake [15] [16] [17].

The disaster resistance rate had increased to $90.7 \%$ of disaster-based hospitals and $74.5 \%$ of all hospitals, but there is a need for all hospitals to address this issue as soon as possible [18].

\section{Conclusion}

Thirteen patients were evacuated from hospitals during the night following an earthquake. Although they were all successfully evacuated without incident, transporting patients during the day if there is no risk of building collapse should be considered. In this instance, it was possible to transport the patients by ambulance, but if the number of patients who require transport is higher, transport procedures that include DMAT, the Self-Defense Force, and private organizations should be considered. A plan for evacuation priority should be prepared before the next disaster.

\section{Acknowledgements}

We would like to thank Tottori DMAT and EMT staff for treating patients and Editage (https://www.editage.com/) for their writing support.

\section{Ethical Approval and Informed Consent}

This study was approved by the institutional review board and ethics committee 
of Tottori University (approval no.). All subjects provided informed consent. The study protocol conformed to the ethical guidelines of the Declaration of Helsinki for research involving human subjects.

\section{Conflicts of Interest}

The authors declare no conflicts of interest regarding the publication of this paper.

\section{References}

[1] Youichi, Y., Hisayoshi, K., Takashi, O. and Fumio, O. (2017) Lessons Learned from the Total Evacuation of a Hospital after the 2016 Kumamoto Earthquake. Journal of Emergency Management, 15, 259-263. https://doi.org/10.5055/jem.2017.0334

[2] Fukae, K. (2017) Experience of Evacuation of All Inpatients and Abeyance of Hospital Function Caused by the 2016 Kumamoto Earthquake. Japanese Journal of Cardiovascular Surgery, 46, 63. https://doi.org/10.4326/jjcvs.46.63 https://www.jstage.jst.go.jp/article/jjcvs/46/2/46_63/_pdf

[3] Shuichi, F. (2016) Practice and Challenges of Hospital Evacuation. Nippon Medical News, 4830, 20-23.

https://mol.medicalonline.jp/library/journal/download?GoodsID=af9mdcla/2016/0 04830/010\&name $=0020-0023$ j\&UserID $=1100006327-00 \&$ base $=$ jamas_pdf

[4] Tohoku University (2020) Tohoku University Disaster Management Manual. https://www.hosp.tohoku.ac.jp/pc/pdf/saigai-manual.pdf

[5] Schultz, C.H., Koenig, K.L. and Lewis, R.J. (2003) Implications of Hospital Evacuation after the Northridge, California Earthquake. The New England Journal of Medicine, 348, 1349-1355. https://doi.org/10.1056/NEJMsa021807

[6] Honma, M. (2020) Policy for Providing Aid for Hospital Evacuations. Ministry of Health, Labour and Welfare, Chiyoda.

https://www.tottori-u.ac.jp/emergency/files/34734.pdf

[7] Ukai, T. (1997) The Great Hanshin-Awaji Earthquake and the Problems with Emergency Medical Care. Renal Failure, 19, 633-645.

https://doi.org/10.3109/08860229709109029

[8] Junichiro, J., Kazama, I.N. and Yutaka, K. (2012) Mass Evacuation of Hemodialysis Patients from the Great East Japan Earthquake. Japanese Journal of Disaster Medicine, 17, 116-170.

https://www.med.niigata-u.ac.jp/nephrol/achievement/research_achievement/catalo g/2012/12_sonota/2012-004.pdf

[9] Yamana, H., Masuno, T., Uchiumi, K., et al. (2016) Sudden Change in Patient with Mild Illness Aboard a Bus That Occurred during Hospital Evacuation Due to the Collapse of the Kinugawa River Embankment. KANTO Journal of Japanese Association for Acute Medicine, 32, 284-287.

[10] Perlman, J.M., Wyllie, J., Kattwinkel, J., Wyckoff, M.H., Aziz, K., Guinsburg, R., et al. (2015) Part 7: Neonatal Resuscitation: 2015 International Consensus on Cardiopulmonary Resuscitation and Emergency Cardiovascular Care Science with Treatment Recommendations (Reprint). Pediatrics, 136, 120-166. https://doi.org/10.1542/peds.2015-3373D

[11] Osuke, I., Akihiko, K., Masanori, I. and Kazuko, W. (2017) Evacuation of a Tertiary Neonatal Centre: Lessons from the 2016 Kumamoto Earthquakes. Neonatology, 112, 92-96. https://doi.org/10.1159/000466681 
[12] Janvier, A., Leblanc, I. and Barrington, K.J. (2008) Nobody Likes Premies: The Relative Value of Patients' Lives. Journal of Perinatology, 28, 821-826.

https://doi.org/10.1038/jp.2008.103

[13] Cohen, R., Murphy, B., Ahern, T. and Hackel, A. (2010) Regional Disaster Planning for Neonatology. Journal of Perinatology, 30, 709-711.

https://doi.org/10.1038/jp.2010.76

[14] Klein, K.R., Pepe, P.E., Burkle, F.M., Nagel, N.E. and Swienton, R.E. (2008) Evolving Need for Alternative Triage Management in Public Health Emergencies: A Hurricane Katrina Case Study. Disaster Medicine and Public Health Preparedness, 2, S40-S44. https://doi.org/10.1097/DMP.0b013e3181734eb6

[15] Ferdousi, S. and Rahman, T. (2010) Earthquake in Bangladesh: How Much We Are Prepared to Face It? Bangladesh Journal of Pathology, 25, 1-2.

https://doi.org/10.3329/bjpath.v25i1.4123

[16] Sultana, S., Rahman, U. and Saika, U. (2013) Earthquake Cause Susceptibility and Risk Mitigation in Bangladesh. ARPN Journal of Earth Sciences, 2, 70-80.

[17] Biswas, A., Mashreky, S.R., Dalal, K. and Deave, T. (2016) Response to an Earthquake in Bangladesh: Experiences and Lesson Learnt. Open Journal of Earthquake Research, 5, 1-6. https://www.researchgate.net/publication/291210717 https://doi.org/10.4236/ojer.2016.51001

[18] Tokyo, Ministry of Health, Welfare and Labour (2018) Results of Surveys on the Status of Making Social Welfare Facility.

https://www.mhlw.go.jp/english/new-info/2018.html

\section{Abbreviations}

DMAT: Disaster Medical Assistance Team 